\title{
Prevalence and Phylogenetic Analyses of Trichuris suis in Pigs in Hunan Province, Subtropical China
}

\author{
Lei Tan ${ }^{1,2,3}$, Aibing Wang ${ }^{1,2,3}$, Jing Yi', Yisong Liu', Jiayu Li4,*, Wei Liư ${ }^{1,2,3, *}$ \\ ${ }^{1}$ College of Veterinary Medicine, Hunan Agricultural University, Changsha, Hunan Province 410128, P.R., China; ${ }^{2}$ Lab of Animal Models and \\ Functional Genomics (LAMFG), The Key Laboratory of Animal Vaccine \& Protein Engineering, College of Veterinary Medicine, Hunan Agricultural \\ University (HUNAU), Changsha, Hunan, 410128, P.R., China; ${ }^{3} R \&$ D Center for Animal Reverse Vaccinology of Hunan Province; ${ }^{4}$ College of \\ Veterinary Medicine, South China Agricultural University, Guangzhou, Guangdong Province 510642, P.R., China
}

\begin{abstract}
Trichuris suis infection in pigs is ubiquitous in intensive and extensive farms, which causes potential threat to human health. The objective of this research was to investigate the prevalence of $T$. suis in pigs in Hunan province. Total 2,267 fresh fecal samples distributed in 28 pig farms from 7 different administrative regions (Hunan province) were evaluated for the existence of $T$. suis eggs using saturated $\mathrm{NaCl}$ floating method. The average infection rate of $T$. suis in pigs was $8.91 \%$ in Hunan province. To determine genetic variation of the gained $T$. suis isolates in the present study, the internal transcribed spacer (ITS) regions from nuclear ribosomal DNA (rDNA) of 7 . suis isolates were cloned and analyzed. Nucleotide diversities were 1.0-3.5\% and 0-3.8\% for ITS-1 and ITS-2, respectively. Phylogenetic analyses indicated that all isolates collected in the present study and T. suis available in Genbank generated a monophyletic clade. The present investigation revealed high infection rates of $T$. suis in pigs in Hunan province, which shed light on making effective measures to prevent and control T. suis infection in pigs in Hunan province.
\end{abstract}

Key words: Trichuris suis, prevalence, pig, internal transcribed spacer (ITS), Hunan province

Trichuris suis, belonging to genera Trichuris, which exists in various mammals, including domestic pigs, wild pigs, humans as well as other primates, is an intestinal parasite which can lead to Trichuriosis [1]. Pigs obtain T. suis after ingestion of raw water, fodder, and vegetables contaminated by cysts accidentally. The most common clinical symptoms include magersucht, anemia, diarrhea, mucosal hemorrhage and hydropsy [2]. T. suis is identified as one of the most widespread pathogenic parasites, leading to decreased feed efficiency of pigs, which brings serious economic losses to pig industries globally $[3,4]$. Pig-breeding has been a traditional and preponderant industry in Hunan province, the productive value of which has been exceeding grain plant since 1997. The same data also shows that pig-breeding industry already takes a crucial part in livestock husbandry of Hunan province that directly closes to the agricultural economy and lives of people. However, few re-

\footnotetext{
- Received 26 July 2018, revised 15 September 2018, accepted 5 October 2018.

*Corresponding authors (weiliupro@163.com; hnnydxsyljy@126.com)

(c) 2018, Korean Society for Parasitology and Tropical Medicine

This is an Open Access article distributed under the terms of the Creative Commons Attribution Non-Commercial License (http://creativecommons.org/licenses/by-nc/4.0) which permits unrestricted non-commercial use, distribution, and reproduction in any medium, provided the original work is properly cited.
}

ports are available associated with the prevalence and molecular characteristics of T. suis in pigs in Hunan province. The present research was conducted to identify the prevalence and epidemic characteristics of T. suis infection from intensive and extensive farms in Hunan province of subtropical China. Moreover, the phylogenetic tree based on ITS-2 sequences was reconstructed to ascertain evolutionary relationships between T. suis and other whipworm species.

The present research was conducted from March 2016 to November 2016 (Table 1). A total of 2,267 pigs aged from 2 weeks to 3 years were selected randomly from representative intensive farms (the number of reared pigs $>300)(n=7)$ and extensive farms (the number of reared pigs $\leq 300)(n=21)$ from 7 different administrative regions in Hunan province (Fig. 1). $20.0 \%$ and $10.0 \%$ of pigs were randomly selected from intensive and extensive farms according to the different growth stages, respectively, and fecal samples were collected individually, labeled, frozen with ice packs, and transported to the Department of Parasitology, College of Veterinary Medicine, Hunan Agricultural University for further processing. Each fecal sample (approximately 10-20 g) was examined for $T$. suis eggs using saturated $\mathrm{NaCl}$ floating method. The number 
Table 1. Prevalence of T. suis infection in pigs from different seasons and regions in Hunan province

\begin{tabular}{|c|c|c|c|c|c|c|c|}
\hline Factor & Category & No. tested & No. positive & Prevalence (\%) & Average intensity & $\chi^{2}$ test $^{d}$ & $P$-value \\
\hline Season & $\begin{array}{l}\text { Spring }^{\mathrm{a}} \\
\text { Summer }^{\mathrm{b}} \\
\text { Autumn }^{\mathrm{C}}\end{array}$ & $\begin{array}{l}852 \\
583 \\
832\end{array}$ & $\begin{array}{r}53 \\
46 \\
103\end{array}$ & $\begin{array}{r}6.22 \\
7.89 \\
12.38\end{array}$ & $\begin{array}{l}1,400 \\
1,600 \\
2,400\end{array}$ & 54.2023 & $<0.0001$ \\
\hline Distinct & $\begin{array}{l}\text { Changsha } \\
\text { Loudi } \\
\text { Xiangtan } \\
\text { Changde } \\
\text { Huaihua } \\
\text { Hengyang } \\
\text { Zhangjiajie }\end{array}$ & $\begin{array}{l}324 \\
362 \\
347 \\
305 \\
294 \\
315 \\
320\end{array}$ & $\begin{array}{l}38 \\
32 \\
47 \\
21 \\
25 \\
16 \\
23\end{array}$ & $\begin{array}{r}11.37 \\
8.84 \\
13.54 \\
6.89 \\
8.50 \\
5.08 \\
7.19\end{array}$ & $\begin{array}{l}1,900 \\
1,800 \\
2,300 \\
1,400 \\
2,000 \\
1,100 \\
1,500\end{array}$ & 20.8214 & 0.002 \\
\hline Total & & 2,267 & 202 & 8.91 & 1,700 & & \\
\hline
\end{tabular}

aFrom March to May.

${ }^{b}$ From June to August.

'From September to November.

${ }^{\mathrm{d}}$ Qualitative data between different groups.

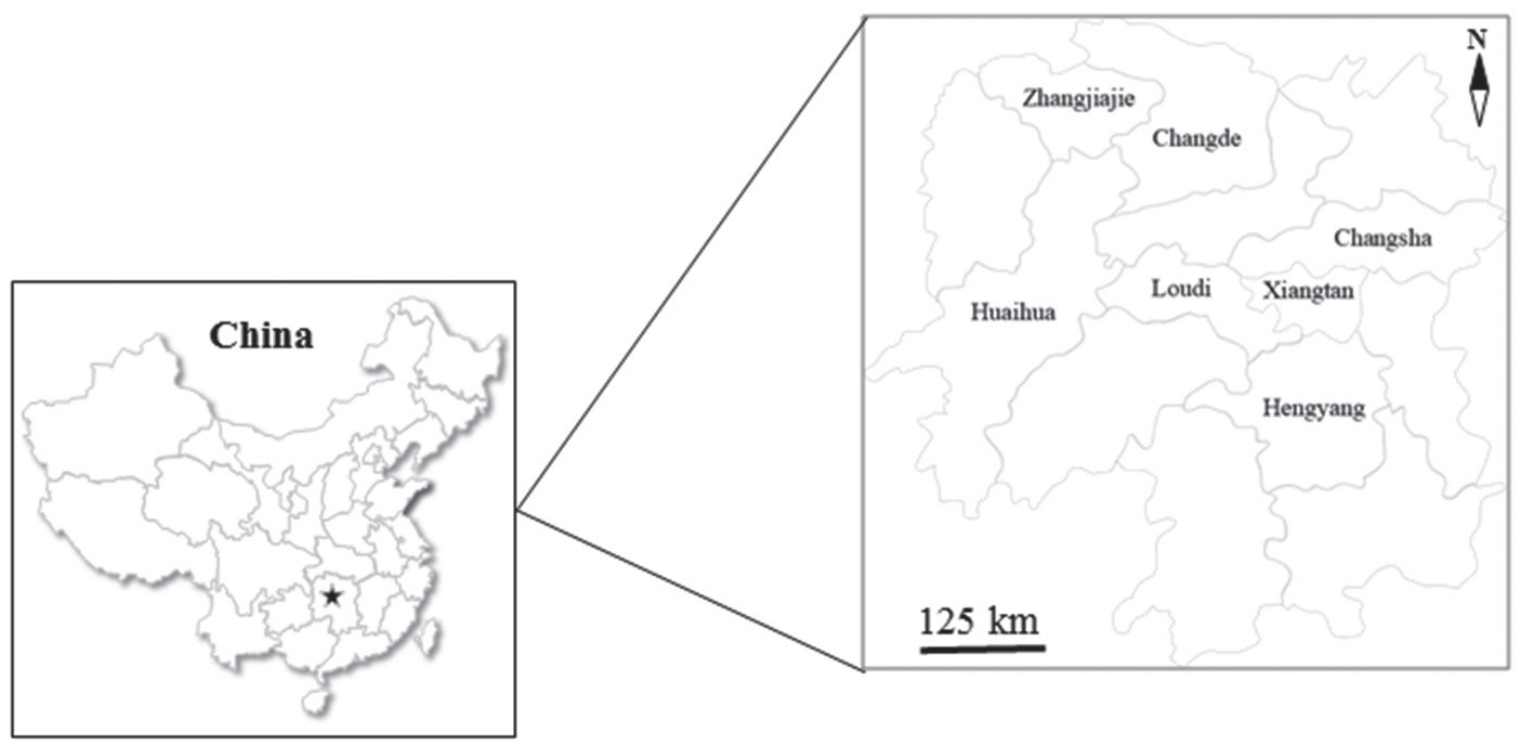

Fig. 1. Seven different administrative regions where a total of 2,267 fecal samples were collected to examine for $T$. suis infection in pigs were labeled in the map of Hunan province (Pentagram), China.

of eggs was counted from per gram fecal sample according to the McMaster method, and each detected egg was distinguished with its morphological features using the light microscope. The caeca of 7 T. suis infected pigs from different regions in Hunan province were collected and evaluated for the presence of adult T. suis. Each adult sample was detached and washed thoroughly in physiological saline, labeled and stored at $-20^{\circ} \mathrm{C}$ in $70 \%$ ethanol till it would be used.

The data of differences in the infection rates of T. suis in pigs of different seasons, geographical locations, growth periods, and raising systems in Hunan province were statistically analysed using SAS version 9.3 (SAS Institute Inc., Cary, North Carolina, USA), with the value of $P<0.05$ being considered to be statistically significant. In addition, $\chi^{2}$ test was conducted to compare the qualitative data between different groups.

Total genomic DNA of 7 adult T. suis isolated from the caeca of the tested pig was extracted using TIANamp Genomic DNA Kit (Beijing, China) following the instructions. The full ITS gene was amplified by PCR according to the report of Liu et al. [5]. Negative sample (no DNA) was used as the control, and then positive PCR products were purified and sequenced in duplicate.

The $3^{\prime}$ end and 5 ' end of the sequence representing ITS-1 and ITS-2 regions were determined by comparison with these of T. suis isolates from pigs [5,6]. Sequences of ITS-1 and ITS-2 representing different isolates and reference sequences avail- 
Table 2. Information of internal transcribed spacers (ITS) gene sequences for the Trichuris species employed in the present research

\begin{tabular}{|c|c|c|c|}
\hline Species & Location & $\begin{array}{l}\text { Sample } \\
\text { codes }\end{array}$ & $\begin{array}{c}\text { Genbank }^{\mathrm{TM}} \\
\text { accession No. }\end{array}$ \\
\hline Trichuris suis & $\begin{array}{l}\text { Changde } \\
\text { Changsha } \\
\text { Huaihua } \\
\text { Hengyang } \\
\text { Loudi } \\
\text { Xiangtan } \\
\text { Zhangjiajie } \\
\text { Hunan (Changsha) } \\
\text { Hunan (Miluo) } \\
\text { Hunan (Yiyang) } \\
\text { Guangdong (Zhanjiang) }\end{array}$ & $\begin{array}{l}\text { HN-CD } \\
\text { HN-CS } \\
\text { HN-HH } \\
\text { HN-HY } \\
\text { HN-LD } \\
\text { HN-XT } \\
\text { HN-ZJJ } \\
- \\
- \\
- \\
-\end{array}$ & $\begin{array}{l}\text { MG656438 } \\
\text { MG656439 } \\
\text { MG656440 } \\
\text { MG656441 } \\
\text { MG656442 } \\
\text { MG656443 } \\
\text { MG656444 } \\
\text { AM992999 } \\
\text { AM993003 } \\
\text { AM993005 } \\
\text { AM993016 }\end{array}$ \\
\hline Trichuris trichiura & $\begin{array}{l}\text { China } \\
\text { China }\end{array}$ & $\begin{array}{l}- \\
-\end{array}$ & $\begin{array}{l}\text { AM992990 } \\
\text { AM992996 }\end{array}$ \\
\hline Trichuris muris & $\begin{array}{l}\text { Spain } \\
\text { Spain }\end{array}$ & $\begin{array}{l}- \\
-\end{array}$ & $\begin{array}{l}\text { FN543201 } \\
\text { AJ299407 }\end{array}$ \\
\hline Trichuris discolor & Spain & - & HE608848 \\
\hline Trichuris ovis & Spain (Andalucia) & - & AJ238220 \\
\hline Trichuris leporis & Spain (Andalucia) & - & AJ251321 \\
\hline Trichuris skrjabini & Unknown & - & AJ489248 \\
\hline Trichuris vulpis & Unknown & - & AM234616 \\
\hline
\end{tabular}

able in the Genbank (Table 2) were aligned using Clustal W in MEGA5 [7]. Nucleotide variations between different samples were determined using the Megalign procedure in DNAStar 5.0 software [8]. Evolutionary relationship was evaluated based on ITS-2 rDNA sequences available in this study using maximum likelihood (ML) method in MEGA5 [7], and the stability of tree was calculated based on 1,000 bootstrap replicates. Meanwhile, other whipworm species were employed as in-groups, with Ascaris suum (Genbank accession number AB571302) as out-group.

A total of 2,267 fecal samples were collected in Hunan province to examine the existence of $T$. suis eggs in pigs. The average infection rate $(8.91 \%)$ of $T$. suis was detected in Hunan province, which is higher than Guangdong province in China (5.07\%) [4], Cambodia (6.6\%) [9] and India (6.6\%) [10], but lower than these reported in Chongqing province (10.13\%) [11] and Tibet Autonomous Region in China (15.2\%) [12]. These data revealed that $T$. suis infection is widely spread in Aisa, mainly in developing countries or regions. Furthermore, different infection rate of $T$. suis in pigs are mainly on account of distinctions in geographical locations, animal welfare, and climate characteristic. The prevalence of T. suis in pigs ranged from $5.08 \%$ to $13.54 \%$ from different geographical regions in Hunan province (Table 1), and the differences were statistically significant $(P<0.05)$, while the highest prevalence was in
Xiangtan city and the lowest prevalence was in Hengyang city.

Seasonal prevalence of $T$. suis infection in pigs ranged from $6.22 \%$ to $12.38 \%(P<0.0001)$. The highest prevalence was in autumn $(12.38 \%)$, followed by summer $(7.98 \%)$, and the lowest prevalence was in spring (6.22\%) (Table 1). It was speculated that the wet and warm environment from April to July in Hunan province is one of the significant factors for the survival and multiplication of $T$. suis, increasing infection rate in pigs. As the pre-patent period of T. suis in the host is nearly 50 days (almost 2 month), which results in higher detection rates of T. suis in summer and autumn, similar with the other intestinal parasite (Balantidium coli) in pigs [13,14].

Infection rates of T. suis from pigs of different growth stages varied from $3.78 \%$ to $15.40 \%(P<0.0001)$, higher in the fatteners group (aged from 2 to 5 months) $(15.40 \%)$ and breeding boars group (aged from 5 to 36 months) (9.75\%), followed by growers group (aged from 1 to 2 months) (8.86\%) and breeding sows group (less than 2 weeks) $(8.62 \%)$, lowest in weaners group (aged from 2 weeks to 1 month) (3.87\%). Furthermore, $7.54 \%(85 / 1,127)$ and $10.26 \%(117 / 1,140)$ fecal samples were confirmed for the existence of T. suis eggs from intensive and extensive pig farms $(P=0.0278)$, respectively. Obviously, prevalence of T. suis from extensive pig farms was more serious than those from intensive pig farms, which might attribute to its poor facilities and unscientific feeding system of extensive pig farms compared with those of intensive pig farms. $2.89 \%$ (17/242) of weaners group, $6.15 \%$ (22/358) of growers group, $14.58 \%$ (35/240) of fatteners group, $6.45 \%$ (6/93) of breeding boars group and $7.73 \%$ (15/194) of breeding sows group were demonstrated to be infected with T. suis from intensive pig farms. Altogether, of 5 groups from extensive pig farms, the infection rate was $4.46 \%(14 / 314), 12.01 \%$ (37/308), $16.24 \%$ $(38 / 234), 20.0 \%(6 / 30)$ and $8.66 \%(22 / 254)(P<0.0001)$, respectively (Table 3 ). The prevalence of $T$. suis increased with the growth stage of pigs, showing that age is an important factor in T. suis prevalence in pigs.

Seven ITS rDNA sequences of 7 isolated adults T. suis were successfully amplified with a fragment length of 1,444-1,450 bp. The complete sequences of the ITS-1 rDNA (687-692 bp), 5.8S rDNA (154 bp) and ITS-2 rDNA (599-606 bp) were analyzed. The deletion/ insertion of nucleotides generated the differences of the length of ITS- 1 and ITS-2 rDNA sequence. The GC content of ITS rDNA sequences were 61.07-61.30\%. Nucleotide variations of ITS- 1 and ITS- 2 rDNA sequences were 0.6$2.1 \%$ and $0-3.2 \%$. The result showed a higher genetic variabil- 
Table 3. Prevalence of T.suis infection in pigs from different growth period groups and different raising systems in Hunan province, China

\begin{tabular}{|c|c|c|c|c|c|c|c|}
\hline Raising system & Pig category & No. tested & No. positive & Prevalence (\%) & Average intensity & $\chi^{2}$ test $^{c}$ & $P$-value \\
\hline$\rho^{a}$ & $\begin{array}{l}\text { Weaners } \\
\text { Growers } \\
\text { Fatteners } \\
\text { Breeding boars } \\
\text { Breeding sows }\end{array}$ & $\begin{array}{r}242 \\
358 \\
240 \\
93 \\
194\end{array}$ & $\begin{array}{r}7 \\
22 \\
35 \\
6 \\
15\end{array}$ & $\begin{array}{r}2.89 \\
6.15 \\
14.58 \\
6.45 \\
7.73\end{array}$ & $\begin{array}{r}800 \\
1,000 \\
2,100 \\
1,000 \\
1,300\end{array}$ & 25.7362 & $<0.0001$ \\
\hline$\|^{\mathrm{b}}$ & $\begin{array}{l}\text { Weaners } \\
\text { Growers } \\
\text { Fatteners } \\
\text { Breeding boars } \\
\text { Breeding sows }\end{array}$ & $\begin{array}{r}314 \\
308 \\
234 \\
30 \\
254\end{array}$ & $\begin{array}{r}14 \\
37 \\
38 \\
6 \\
22\end{array}$ & $\begin{array}{c}4.46 \\
12.01 \\
16.24 \\
20.0 \\
8.66\end{array}$ & $\begin{array}{r}800 \\
1,400 \\
2,200 \\
2,700 \\
900\end{array}$ & 25.3812 & $<0.0001$ \\
\hline I & $\begin{array}{l}\text { Subtotal } \\
\text { Subtotal } \\
\text { Total }\end{array}$ & $\begin{array}{l}1,127 \\
1,140 \\
2,267\end{array}$ & $\begin{array}{r}85 \\
117 \\
202\end{array}$ & $\begin{array}{r}7.54 \\
10.26 \\
8.91\end{array}$ & $\begin{array}{l}1,300 \\
1,700 \\
1,700\end{array}$ & 4.8399 & 0.0278 \\
\hline
\end{tabular}

alntensive pig farms (the number of reared pigs $>300$ ).

${ }^{b}$ Extensive pig farms (the number of reared pigs $\leq 300$ ).

${ }^{\circ}$ Qualitative data between different groups.

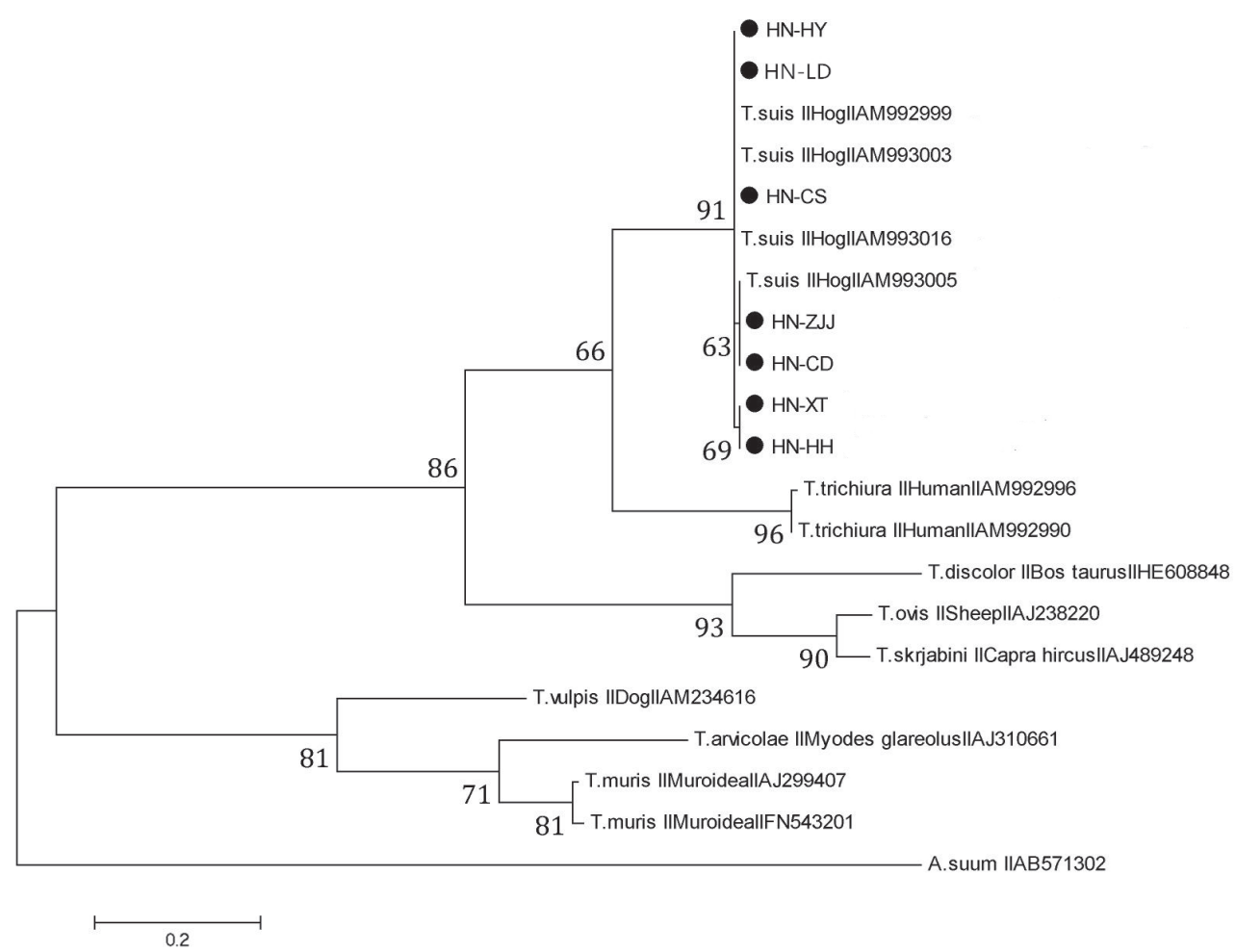

Fig. 2. Phylogenetic tree was generated using maximum likelihood (ML) method to show genetic relationships among examined Trichuris species based on ITS-2 sequences. Ascaris suum (AB571302) was employed as the out-group.

ity than that of previous reports [5], while growing evidence indicated that nucleotide variation in ITS-2 rDNA sequence in T. suis was higher than other nematodes $[5,15]$.

In order to ascertain the evolutionary relationships between T. suis and other whipworm species, phylogenetic tree based on ITS-2 rDNA sequence was reconstructed using ML method in MEGA5. All isolates collected in the present study and $T$. suis available in Genbank generated a monophyletic clade, and these isolates were randomly distributed (Fig. 2), which indicated that in the process of evolution, there was no existence of geographical isolates of T. suis [16]. The result of this phylogenetic tree supported that Trichuris in pigs were more similar to Trichuris in humans compared with other Trichuris species, and obvious inter-species nucleotide variations in ITS- 1 and 
ITS-2 rDNA sequences among those 2 Trichuris species were observed $[5,15]$. It was suggested that Trichuris gained from pigs and humans represented 2 discrepant populations, consistent with the results of the previous studies $[15,17]$. The results revealed that Trichuris from different hosts belonged to 3 distinct groups, in agreement with previous study of evolutionary relationships in $T$. suis and other whipworm species based on nuclear and mitochondrial genes [18,19].

Historically, T. suis has universally been considered as an unimportant intestinal parasite in pigs owing to limited reports available in China. In the present study, high infection rate (8.91\%) of T. suis in pigs was detected in Hunan province. The prevalence may be mainly related to geographical regions, seasons, raising systems and growth stages of pigs. Therefore, effective integrated strategies and measures should be taken to control T. suis infection in pigs. For instance, pig farmers should make regular anti-T. suis treatment project and improve feeding condition and management for pigs. Phylogenetic analysis indicated that all $T$. suis isolates collected in this study and those in Genbank database generated a monophyletic clade. This is the first exhaustive, comprehensive survey of $T$. suis infection from intensive and extensive farms in Hunan province, subtropical China.

\section{ACKNOWLEGMENTS}

Project support was provided in part by grants from the Bureau of Animal Husbandry and Fisheries, Hunan Province (20160875), the Department of Science and Technology, Hunan Province (2016NK2014) and the Program of Local Standards in Hunan Province (Grant No. 5026301-1112006).

\section{CONFLICT OF INTERESTS}

The authors declare that they have no competing interests.

\section{REFERENCES}

1. Meekums H, Hawash MB, Sparks AM, Oviedo Y, Sandoval C, Chico ME, Stothard JR, Cooper PJ, Nejsum P, Betson M. A genetic analysis of Trichuris trichiura and Trichuris suis from Ecuador. Parasit Vectors 2015; 8: 168.

2. Roepstorff A, Murrell KD. Transmission dynamics of helminth parasites of pigs on continuous pasture: Ascaris suum and Trichuris suis. Int J Parasitol 1997; 27: 563-572.

3. Roepstorff A, Mejer H, Nejsum P, Thamsborg SM. Helminth parasites in pigs: new challenges in pig production and current research highlights. Vet Parasitol 2011; 180: 72-81.

4. Weng YB, Hu YJ, Li Y, Li BS, Lin RQ, Xie DH, Gasser RB, Zhu $X Q$. Survey of intestinal parasites in pigs from intensive farms in Guangdong Province, People's Republic of China. Vet Parasitol 2005; 127: 333-336.

5. Liu GH, Zhou W, Nisbet AJ, Xu MJ, Zhou DH, Zhao GH, Wang SK, Song HQ, Lin RQ, Zhu XQ. Characterization of Trichuris trichiura from humans and T. suis from pigs in China using internal transcribed spacers of nuclear ribosomal DNA. J Helminthol 2014; 88: 64-68.

6. Cutillas C, de Rojas M, Ariza C, Ubeda JM, Guevara D. Molecular identification of Trichuris vulpis and Trichuris suis isolated from different hosts. Parasitol Res 2007; 100: 383-389.

7. Tamura K, Peterson D, Peterson N, Stecher G, Nei M, Kumar S. MEGA5: molecular evolutionary genetics analysis using maximum likelihood, evolutionary distance, and maximum parsimony methods. Mol Biol Evol 2011; 28: 2731-2739.

8. Burland TG. DNASTAR's Lasergene sequence analysis software. Methods Mol Biol 2000; 132: 71-91.

9. Inpankaew T, Murrell KD, Pinyopanuwat N, Chhoun C, Khov K, Sem T, Sorn S, Muth S, Dalsgaard A. A survey for potentially zoonotic gastrointestinal parasites of dogs and pigs in Cambodia. Acta Parasitol 2015; 60: 601-604.

10. Krishna Murthy CM, Ananda KJ, Adeppa J, Satheesha MG. Studies on gastrointestinal parasites of pigs in Shimoga region of Karnataka. J Parasit Dis 2016; 40: 885-889.

11. Lai M, Zhou RQ, Huang HC, Hu SJ. Prevalence and risk factors associated with intestinal parasites in pigs in Chongqing, China. Res Vet Sci 2011; 91: 121-124.

12. Luo HQ, Wang XQ, Zhang H, Lan YF, Qiu G, Li JK, Yangzom C. Investigation of intestinal parasite infections in Tibetan pigs in Nyingchi of Tibet. Chin J Vet Sci 2016 (In Chinese).

13. Choubisa SL, Jaroli VJ. Gastrointestinal parasitic infection in diverse species of domestic ruminants inhabiting tribal rural areas of southern Rajasthan, India. J Parasit Dis 2013; 37: 271-275.

14. Yin DM, Lv CC, Tan L, Zhang TN, Yang CZ, Liu Y, Liu W. Prevalence of Balantidium coli infection in sows in Hunan province, subtropical China. Trop Anim Health Prod 2015; 47: 1637-1640.

15. Nissen S, Al-Jubury A, Hansen TV, Olsen A, Christensen H, Thamsborg SM, Nejsum P. Genetic analysis of Trichuris suis and Trichuris trichiura recovered from humans and pigs in a sympatric setting in Uganda. Vet Parasitol 2012; 188: 68-77.

16. Dolezalova J, Obornik M, Hajduskova E, Jirku M, Petrzelkova KJ, Bolechova P, Cutillas C, Callejon R, Jozef J, Berankova Z, Modry D. How many species of whipworms do we share? Whipworms from man and other primates form two phylogenetic lineages. Folia Parasitol 2015; 62: 63.

17. Liu GH, Gasser RB, Su A, Nejsum P, Peng L, Lin RQ, Li MW, Xu MJ, Zhu XQ. Clear genetic distinctiveness between human- and pig-derived Trichuris based on analyses of mitochondrial datasets. PLoS Negl Trop Dis 2012; 6: e1539.

18. Callejón R, Robles Mdel D, Panei CJ, Cutillas C. Molecular di- 
versification of Trichuris spp. from Sigmodontinae (Cricetidae) rodents from Argentina based on mitochondrial DNA sequences. Parasitol Res 2016; 115: 2933-2945.

19. Callejón R, Halajian A, Cutillas C. Description of a new species,
Trichuris ursinus n. sp. (Nematoda: Trichuridae) from Papio ursinus Keer, 1792 from South Africa. Infect Genet Evol 2017; 51: 182-193. 